\title{
Maximum Temperature on the Carbon Stripping Foil In the Spallation Neutron Source
}

\section{BNL/SNS TECHNICAL NOTE}

NO. 45

\author{
C.J. Liaw, Y.Y. Lee, J. Alessi, J. Tuozzolo
}

June 18, 1998

ALTERNATING GRADIENT SYNCHROTRON DEPARTMENT BROOKHAVEN NATIONAL LABORATORY

UPTON, NEW YORK 11973 


\title{
The Maximum Temperature On The Carbon Stripping Foil
}

\section{In the Spallation Neutron Source}

\author{
C.J. Liaw, Y.Y. Lee, J. Alessi, J. Tuozzolo \\ Brookhaven National Laboratory, New York
}

\subsection{Introduction}

Injection into the accumulator ring of the Spallation Neutron Source (SNS) will be done by stripping $\mathrm{H}^{-}$beam provided by the Linac. A carbon foil [1,2] will be used to fully strip the electronics at one location. The foil will be located in the gap of a dipole magnet which is part of the injection orbit bump. The $1 \mathrm{GeV} \mathrm{H}^{-}$beam from Linac has a pulse length of $1 \mathrm{~ms}$ with repetition rate of $60 \mathrm{~Hz}$ and an average current of $18.2 \mathrm{~mA}$. The energy lost on the carbon foil will heat the foil and could destroy it. The lifetime of the stripping foil will depend on the maximum temperature of the carbon foil, the repetition rate of the beam, and the fabrication method of the carbon foil. The performance of the foils fabricated by various methods has been reported previously [3,4,5]. This report focuses on determining the maximum temperatures that the carbon stripping foil can operate at before failure. Analysis was done for $220 \mu \mathrm{g} / \mathrm{cm}^{2}$ and $400 \mu \mathrm{g} / \mathrm{cm}^{2}$ foils.

(See Section 2.0.) A $225 \mu \mathrm{g} / \mathrm{cm}^{2}$ thick carbon foil was tested to verify the analysis result. (See Section 3.0.) More testing to determine foil lifetime is planned.

\subsection{Thermal analyses of the carbon stripping foil}

The carbon foil $(10 \mathrm{~mm} \times 30 \mathrm{~mm})$ will be mounted in a $20 \mathrm{~cm}$ diameter stainless steel beam pipe in the injection area of SNS. Fig. 1 shows the layout of SNS injection foil and the model that was used for the thermal analysis.

\subsection{Assumptions}

The assumptions for the analysis are as follows:

1. SNS injected beam properties [1,2]:

\begin{tabular}{|l|c|}
\hline Kinetic energy & $1 \mathrm{GeV}$ \\
\hline Beam pulse length & $1 \mathrm{~ms}$ \\
\hline Repetition rate & $60 \mathrm{~Hz}$ \\
\hline Ave. beam current (1 MW ave. power) & $18.2 \mathrm{~mA}$ \\
\hline RMS emittance of the beam in both dir.'s & $0.14 \pi \mathrm{mm}-\mathrm{mr}$ \\
\hline Beta function & $17.4 \mathrm{~m} \mathrm{(x} \mathrm{dir.)}$ \\
& $4.56 \mathrm{~m}$ (y dir.) \\
\hline Beam current density distribution on the foil & $2-\mathrm{D}$ Gaussian \\
& distribution \\
\hline Beam size @ 1- $\sigma$ & $3.1 \mathrm{~mm}$ (x.dir.) \\
& $1.6 \mathrm{~mm}$ (y.dir.) \\
\hline
\end{tabular}

2. The power density, $\mathrm{P}$, on the carbon foil could be derived using the following equation [8]: (for the case of stripping a $1 \mathrm{GeV} \mathrm{H}^{-}$beam) 
where $\mathrm{t}$ is the foil thickness in $\mathrm{g} / \mathrm{cm}^{2}$ and $\mathrm{I}$ is the current density in $\mathrm{A} / \mathrm{m}^{2}$.

3. Material properties [7]:

\begin{tabular}{|l|c|c|}
\hline & Carbon & S. Steel \\
\hline Density, $\rho, \mathrm{kg} / \mathrm{m}^{3}$ & 1900 & 8044 \\
\hline Thermal cond., $\mathrm{k}, \mathrm{W} / \mathrm{m}-\mathrm{K}$ & 246 & 16.2 \\
\hline Heat Capacity, c, J/kg- K & 1000 & 502 \\
\hline Rad. View factor, $\mathrm{f}$ & 1 & 1 \\
\hline Rad. Emissivity, $\varepsilon$ & 0.8 & 0.05 \\
\hline
\end{tabular}

4. The convection coefficient at the outer surface of the pipe, $h=8.17 \mathrm{~W} / \mathrm{m}^{2}-\mathrm{K}$

5. Stefan-Boltzmann constant, $\sigma=5.67 \times 10^{-8} \mathrm{~W} / \mathrm{m}^{2}-\mathrm{K}^{4}$

6. Neglect the heat conduction from the foil to the foil holder.

7. Ambient temperature, $\mathrm{T}_{\mathrm{o}}=297 \mathrm{~K}$.

8. Initial condition: all components@ $297 \mathrm{~K}$.

\subsection{Mathematical models}

\subsubsection{The ANSYS model}

The governing equations for the heat transfer analysis are expressed as follows [6]:

On the carbon foil:

$$
\nabla^{2} \mathrm{~T}_{\mathrm{c}}+1 /\left(\mathrm{k}_{\mathrm{c}} \mathrm{t}_{\mathrm{c}}\right)\left[\mathrm{P}-2 \sigma \varepsilon_{\mathrm{c}}\left(\mathrm{T}_{\mathrm{c}}{ }^{4}-\mathrm{T}_{\mathrm{b}}^{4}\right)\right]=1 / \alpha_{\mathrm{c}} \partial \mathrm{T}_{\mathrm{c}} / \partial \tau
$$

where $\nabla^{2}=\partial^{2} / x^{2}+\partial^{2} / y^{2}+\partial^{2} / z^{2}, \alpha_{c}=k_{c} / \rho_{c} c_{c}, T_{c}=$ temperature on the foil, $\mathrm{t}_{\mathrm{c}}=$ thickness of the foil, $\tau=$ time, and all other parameters are defined in Section 2.1. Subscript, $\mathrm{c}$, is for the carbon foil.

On the beam pipe:

$$
\nabla^{2} \mathrm{~T}_{\mathrm{b}}+1 /\left(\mathrm{k}_{\mathrm{b}} \mathrm{t}_{\mathrm{b}}\right)\left[2 \sigma \varepsilon_{\mathrm{b}}\left(\mathrm{T}_{\mathrm{c}}^{4}-\mathrm{T}_{\mathrm{b}}^{4}\right)-\mathrm{h}\left(\mathrm{T}_{\mathrm{b}}-\mathrm{T}_{\mathrm{c}}\right)\right]=1 / \alpha_{\mathrm{b}} \partial \mathrm{T}_{\mathrm{b}} / \partial \tau
$$

where $\nabla^{2}=\partial^{2} / x^{2}+\partial^{2} / y^{2}+\partial^{2} / z^{2}, \alpha_{b}=k_{b} / \rho_{b} c_{b}, T_{b}=$ temperature on the beam pipe, $\mathrm{t}_{\mathrm{c}}=$ thickness of the foil, $\tau=$ time, and all other parameters are defined in Section 2.1. Subscript, $b$, is for the beam pipe.

An ANSYS model of the system was developed to solve Eq. (2) and Eq. (3) simultaneously. The beam properties, material properties, heat loads and the other assumptions are shown in Section 2.1. This model included the radiation heat transfer between the carbon foil and the stainless steel beam pipe, heat conduction through the foil to its base, a natural convection condition on the outer surface of the beam pipe, and a Gaussian distribution for the power density from the beam (in the $\mathrm{x}$ and $\mathrm{y}$ directions) on the foil. Two thicknesses, $220 \mu \mathrm{g} / \mathrm{cm}^{2}$ and $400 \mu \mathrm{g} / \mathrm{cm}^{2}$, were analyzed. After a few lengthy transient and non-linear numerical analyses, the maximum temperature on the foil verse time was plotted (Fig. 2 and Fig. 3). The plots show the initial two cycles when beam first starts hitting the foil. 
For comparison, a simplified model was developed to verify the correctness of the finite element analysis. This model neglected the heat conduction across the carbon foil and assumed a constant temperature for the inner wall of the beam pipe. Therefore, Eq.(2) (for the carbon foil) could be decoupled from Eq. (3), which resulted in the following ordinary differential equation:

$$
\rho_{c} V_{c} c_{c} d T d d \tau=-2 \sigma f \varepsilon_{c} A_{c}\left(T_{c}^{4}-T_{0}^{4}\right)+P_{c}
$$

where $\mathrm{V}_{\mathrm{c}}=$ volume of the carbon foil, $\mathrm{T}_{\mathrm{c}}=$ temperature on the carbon foil, $\tau=$ time, $\mathrm{A}_{\mathrm{c}}=$ area on the foil surface, and all other parameters are given in Section 2.1. The integrated results of Eq. (4) for the initial two cycles are also shown in Fig. 2 and Fig. 3. (See the phantom lines.)

\subsection{Results}

The analysis results are as follows:

1. Fig. 2 and Fig. 3 show that for both $400 \mu \mathrm{g} / \mathrm{cm}^{2}$ and $220 \mu \mathrm{g} / \mathrm{cm}^{2}$ thick foils, the temperature cycles on the carbon foil become stable after the second heating cycle.

2. During the operation, the maximum temperature on the foil would fluctuate from $955 \mathrm{~K}$ to $3305 \mathrm{~K}$ for the $400 \mu \mathrm{g} / \mathrm{cm}^{2}$ case and from $799 \mathrm{~K}$ to $2928 \mathrm{~K}$ for the $220 \mu \mathrm{g} / \mathrm{cm}^{2}$ case.

3. The maximum temperatures on the foil, which were calculated by the simplified model were slightly higher than those computed by the ANSYS model. This is because that the simplified model does not include the heat conduction effect on the foil.

\subsection{Carbon foil test}

Since there is no pyrometer fast enough to detect the maximum temperature on the carbon foil while stripping the $\mathrm{H}^{-}$beam with a pulse length being shorter than $1 \mathrm{~ms}$, the following test was used as an alternative method to verify the analysis results.

This test was based on the assumption that the carbon foil would fail within a short period of time only if the temperature on the carbon foil is equal or higher than the melting point of the material. Using the equations from Section 2.0, the maximum temperatures on the foil verse energy depositions were calculated analytically. The melting point of carbon $(3973 \mathrm{~K})$ was obtained from a handbook [7]. By measuring the critical energy deposition above which the foils would fail immediately the analysis results could be verified.

\subsection{Test setup}

The test setup (see Fig. 4) included a viewing box, an upstream collimator (a carbon rod with $1 \mathrm{~mm}$ dia. center hole), a $225 \mu \mathrm{g} / \mathrm{cm}^{2}$ carbon foil $(17 \mathrm{~mm}$ x $62 \mathrm{~mm}$ ) mounted on an aluminum frame. The frame was mounted on a linear drive mechanism positioned by a stepping motor so multiple shots at various energies could be taken on the same foil. A Faraday cup (not shown) downstream of the foil detected the beam current. The carbon foil was made by Arizona Carbon Foil Company. It was glued onto the mounting frame along one edge to prevent any restriction when the foil deforms. The foil was positioned $1.83 \mathrm{~cm}$ away from the collimator so that the beam size is very close to the aperture of the collimator. 
The $750 \mathrm{keV} \mathrm{H}^{-}$ion beam, generated in Linac of BNL, was used in the test. The pulse length was 0.5 $\mathrm{ms}$ and the repetition rate was $7.5 \mathrm{~Hz}$. Different energy depositions on the foil were achieved by varying the beam current. The test was performed with the foil under the vacuum. The beam size and current density at the foil location were carefully measured before the test, using the emittance heads.

\subsection{Theoretical predictions}

The power densities given in Fig. 5 were calculated based on the beam size given by the emittance measurements, the beam current, and the energy of the beam. The maximum temperatures on the foil verse the applied power densities (see Fig. 6) were derived by integrating Eq. (4) with the material properties, given Section 2.1. Since the pulse length of the test beam was only $0.5 \mathrm{~ms}$, the heat conduction on the foil would not be significant and could be neglected.

\subsection{Test results}

Fig. 7 shows a picture of the carbon foil with beam on it. It is a 20 seconds time exposure with multiple shots on the foil. The bright glow in the center is from the beam heating the carbon foil. Two typical pictures of the undamaged targets after the test are shown in Fig. 8.(The predicted maximum temperatures for them were about $3000 \mathrm{~K}$ and $3600 \mathrm{~K}$ respectively). Fig. 9 shows a typical damaged target after the beam test. (The predicated maximum temperature for it was above $5000 \mathrm{~K})$. Eight tests were conducted at increasing current levels. The results are summarized in Fig. 10. When the carbon foil failed it was detected by a decrease in the $\mathrm{H}+$ beam current on the Faraday cup downstream of the foil. The foil was also inspected under a microscope after the test. The results showed that

1. The beam current densities that predicated a temperature above the carbon melting temperature $(3973 \mathrm{~K})[7]$ caused the foil to fail after < 1 minute of running time.

2. The beam current densities that predicted a temperature below the carbon melting temperature did not affect the performance of the foil after 10 minutes of testing.

3. Even at operating temperatures below the foil melting point there was permanent deformation of the foil. From the current readings this deformation did not affect the performance of the foil.

\subsection{Further test planned}

The next set of tests will compare the foils made by LANL(using the mCADAD method [3,4]) and the foils made by Arizona Carbon Foil Company. The foils will be exposed to the test beam for longer periods of time. A single foil design or "postage stamped" double foils will be evaluated and both $200 \mu \mathrm{g} / \mathrm{cm}^{2}$ and $400 \mu \mathrm{g} / \mathrm{cm}^{2}$ foil thicknesses will be evaluated. Every foil will be installed on a foil holder, which has the same configuration as that will be used in SNS.

\section{References}

1. NSNS Project Design Manual, 1998, Brookhaven National Laboratory.

2. NSNS Conceptual Design Report, 1997, Brookhaven National Laboratory.

3. I Sugai, et al, "Development of thick, long-lived carbon stripper foils for PSR of LANL", Nucl. Instr. And Meth. A 362 (1995)70.

4. M.J. Borden, "Long-life Carbon-fiber-supported carbon stripper foils", Nucl. Instr. And Meth. A 303 (1991)63. 
5. I Sugai, et al, " A new method for making long-lived carbon foils for heavy Ion beam strippers", Nucl. Instr. And Meth. A 236 (1985)576.

6. J.P. Holman, “Heat Transfer" $5^{\text {th }}$ Ed., McGraw Hill Book Company.

7. Brady, Clauser, \& Vaccari, " Materials Handbook" $14^{\text {th }}$ Ed., McGraw Hill Book Company.

8. C. Bovet, et al, " A selection of formula and data useful for the design of A.G. Synchrotrons", CERN/MPS-SI/Int DL/70/4, 1970. 


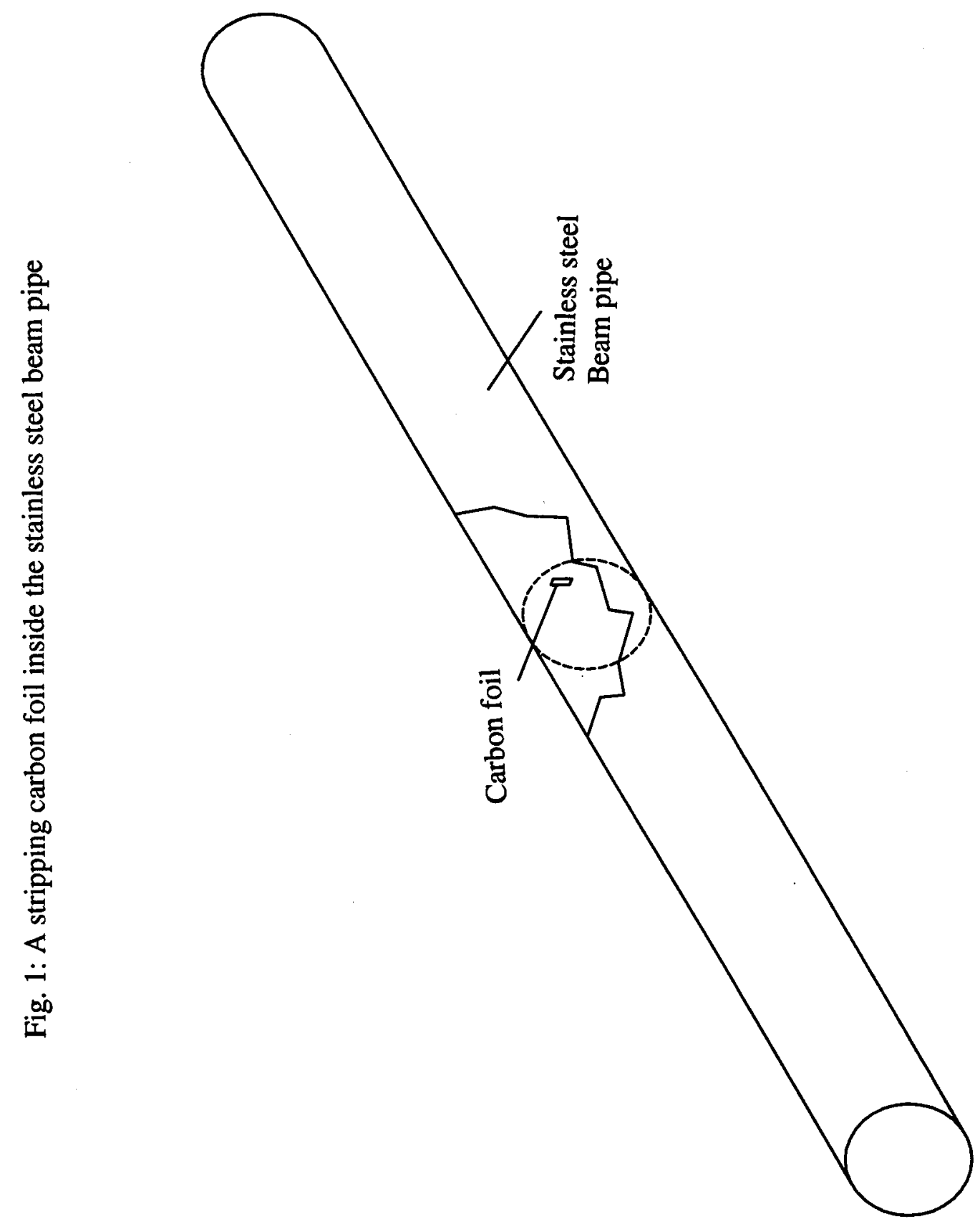




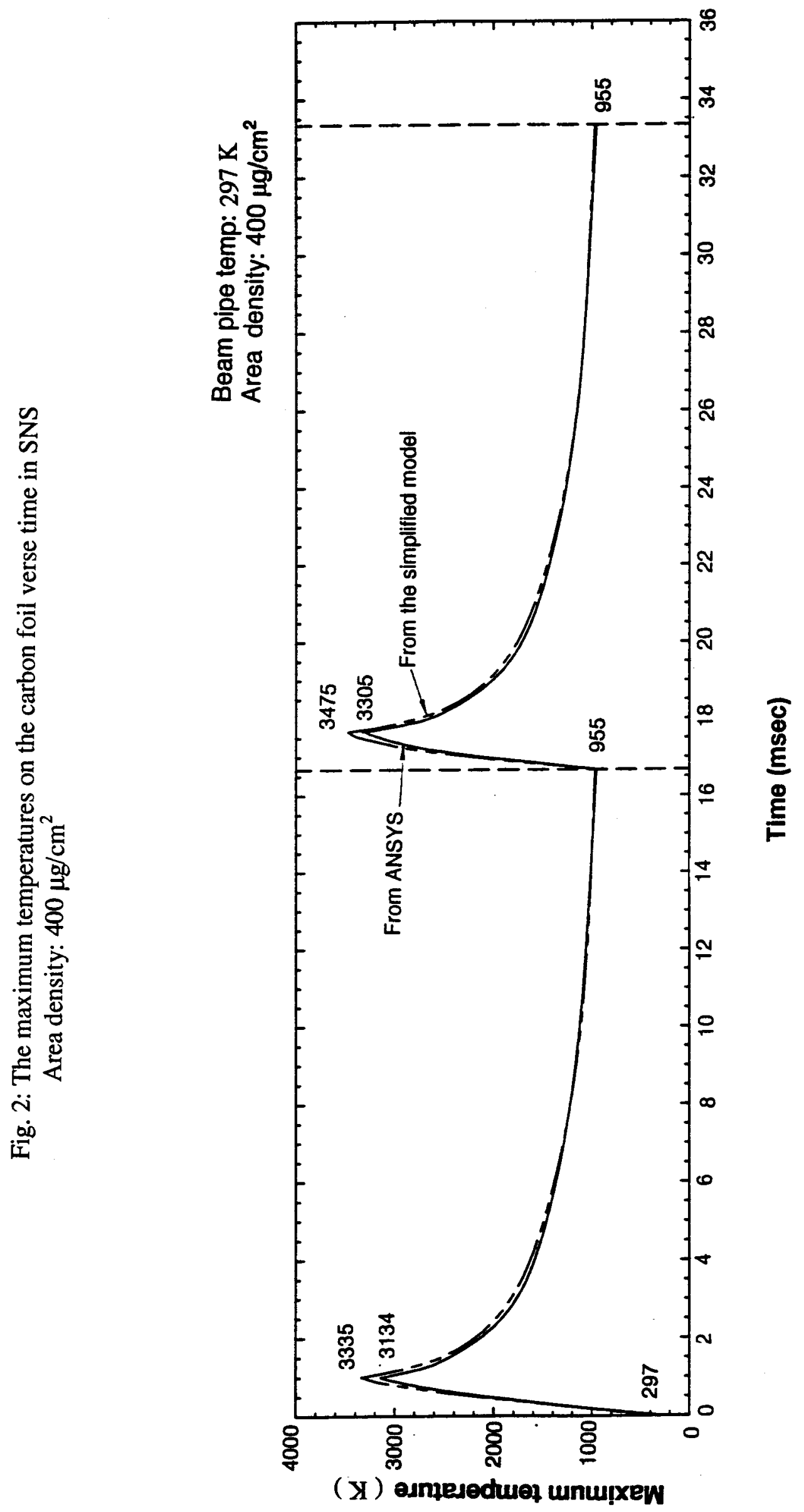



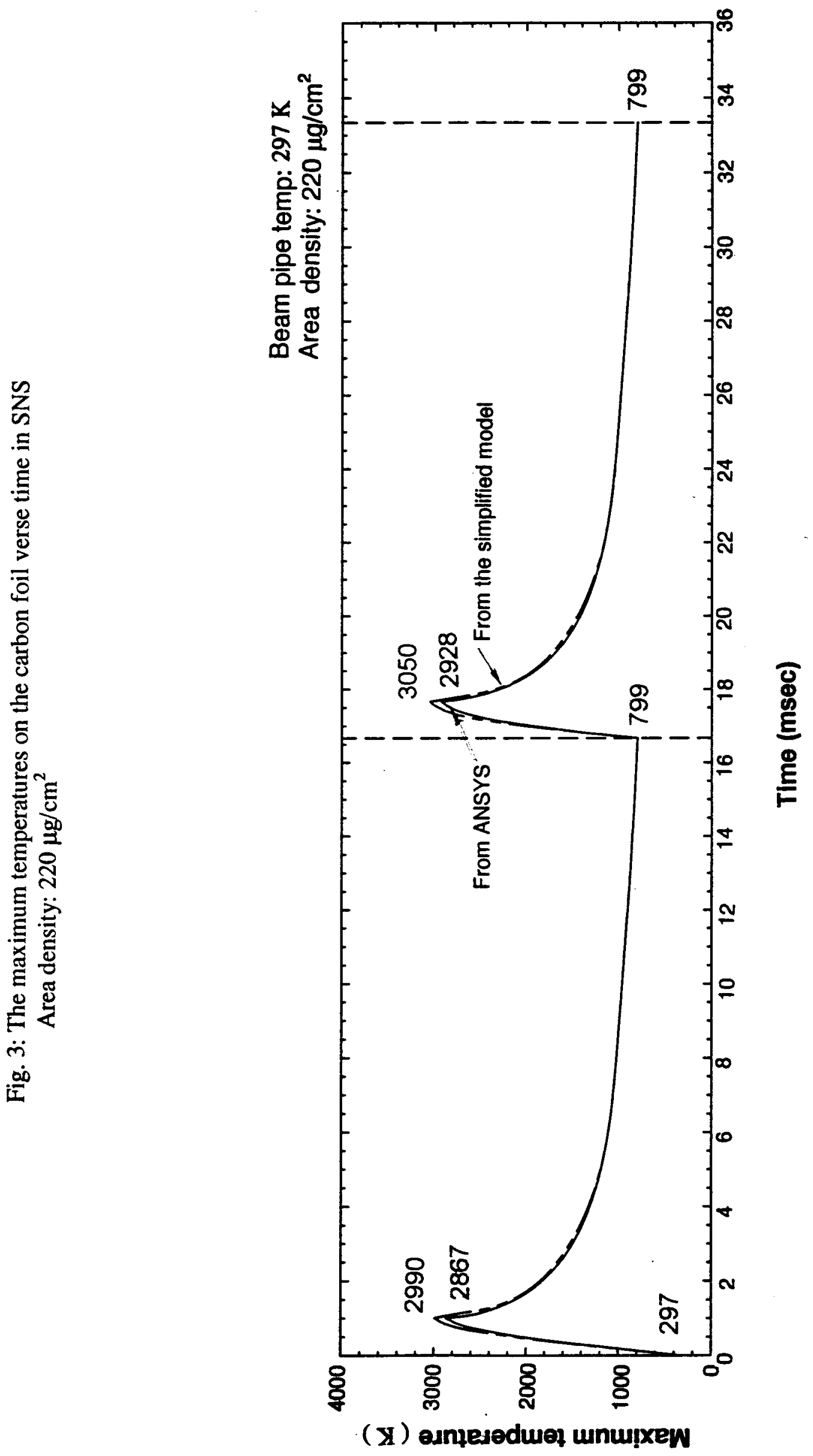


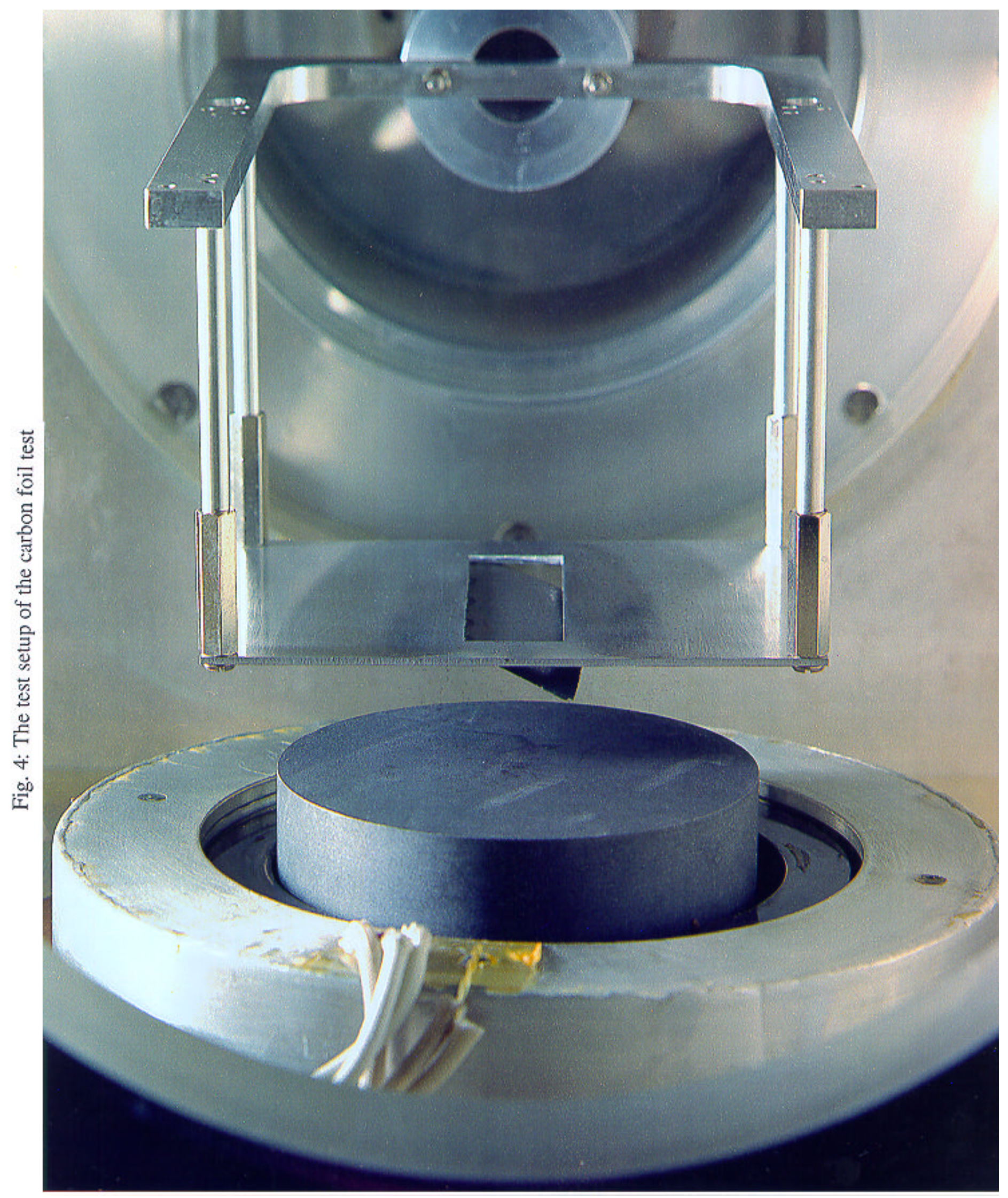




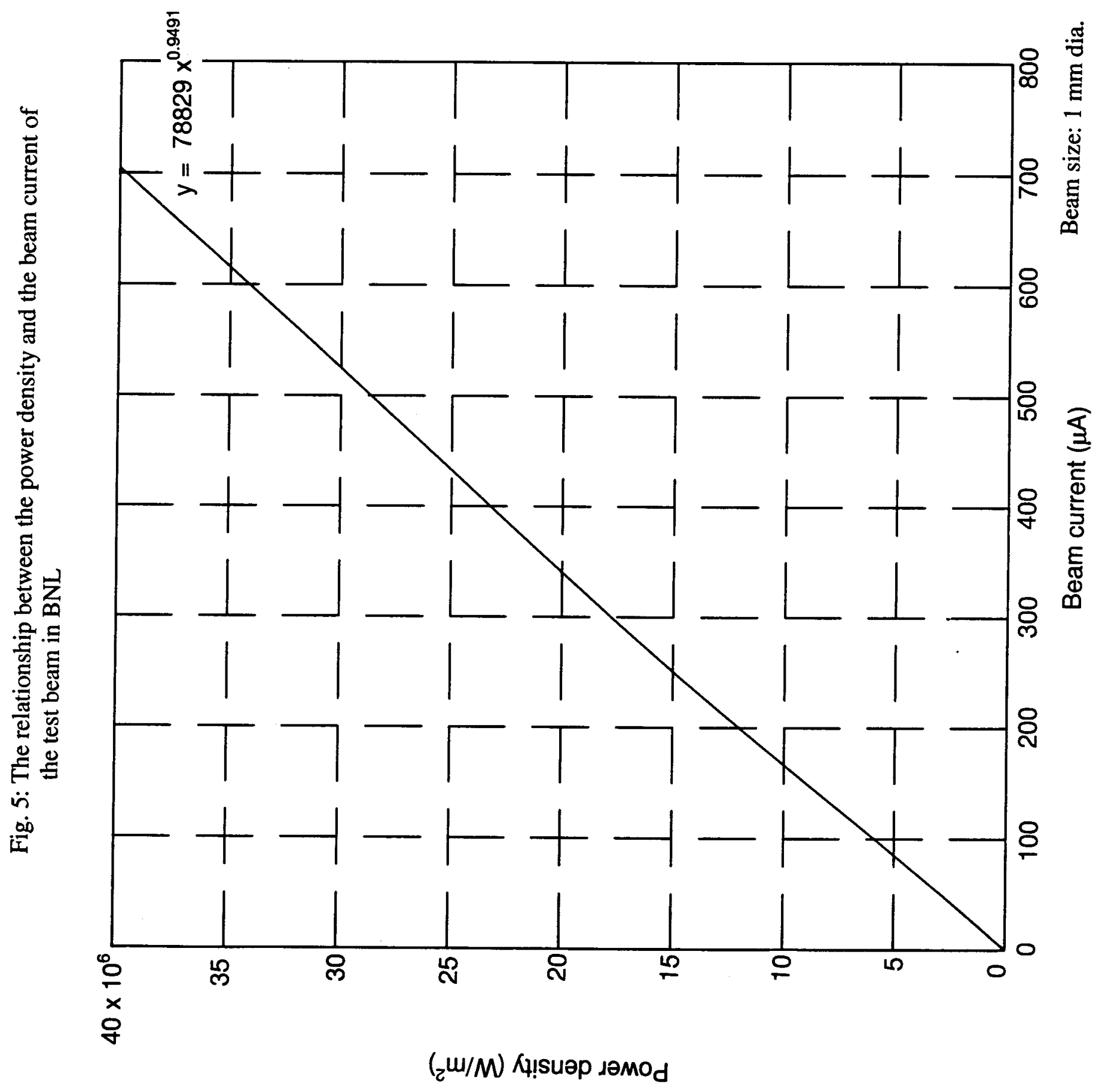




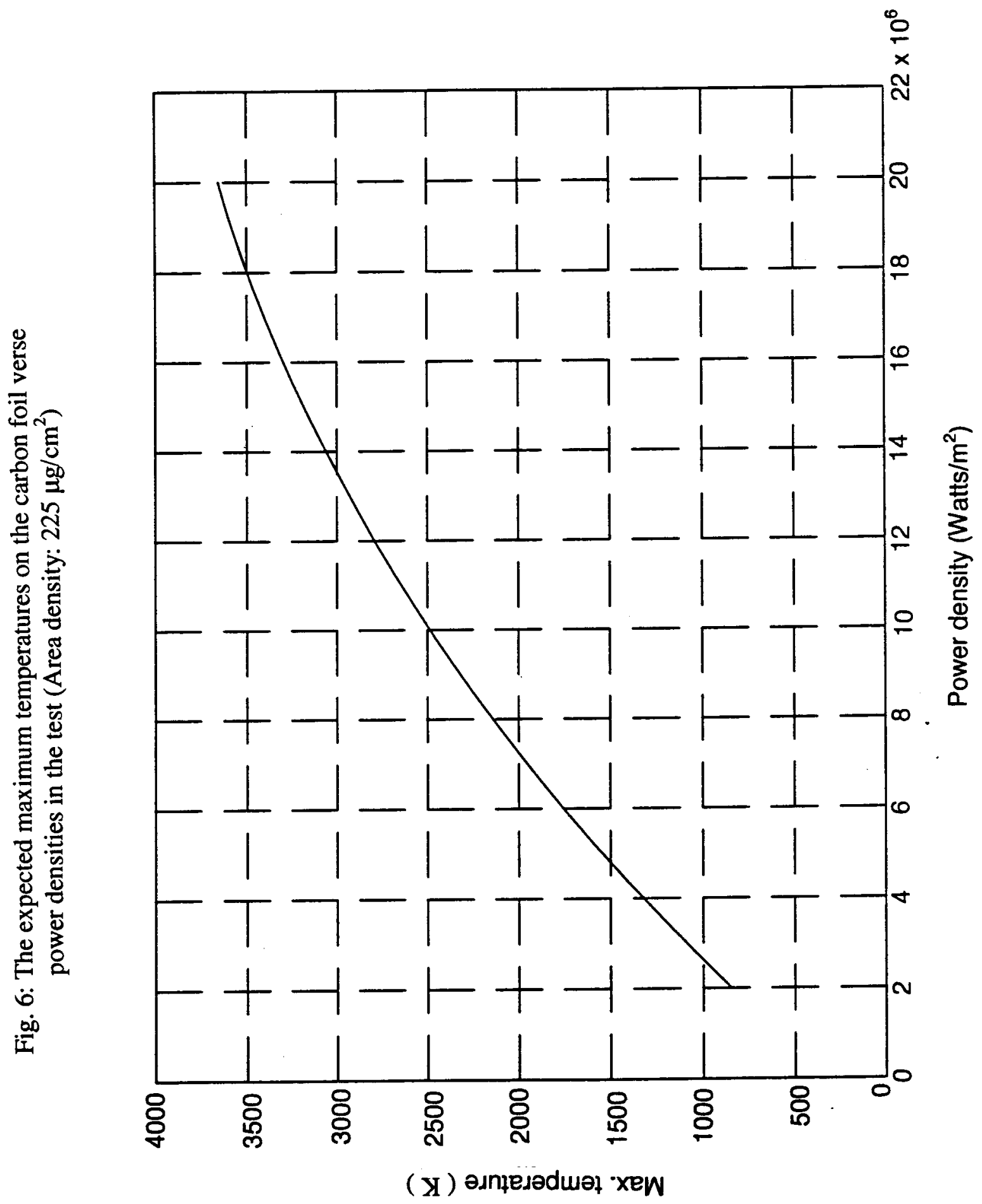




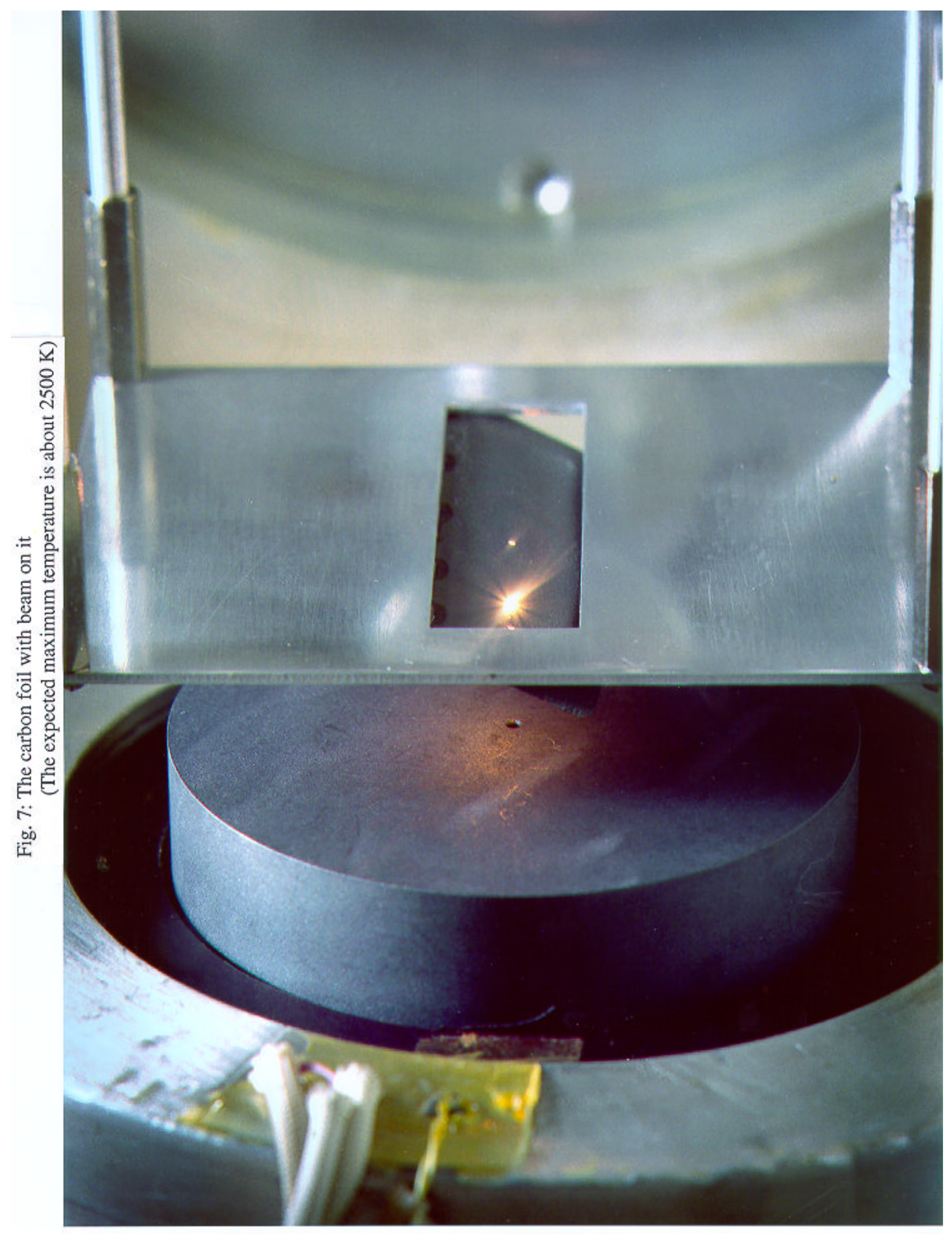


Predicated maximum temperature: $3000 \mathrm{~K}$

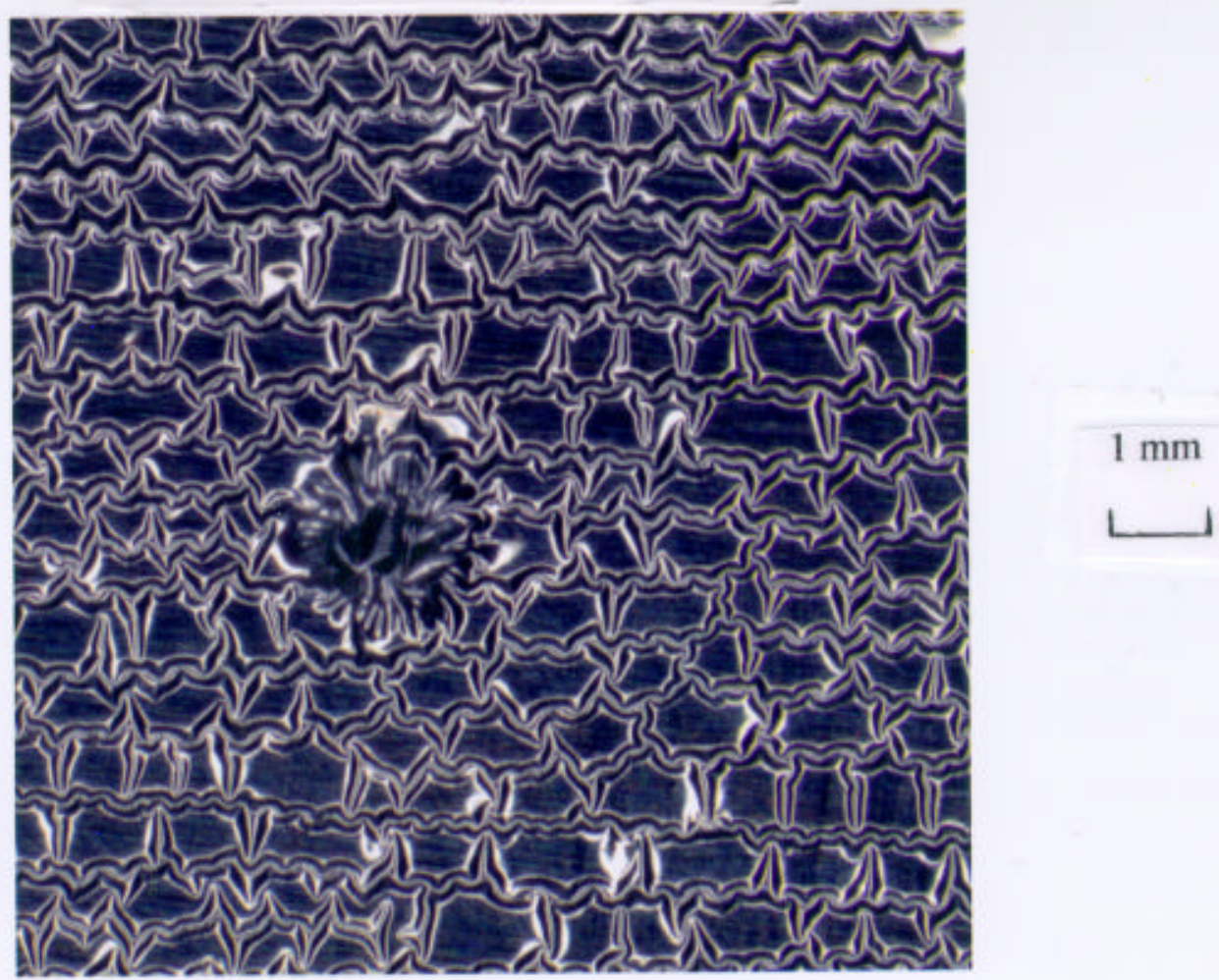

Predicated maximum temperature: $3600 \mathrm{~K}$

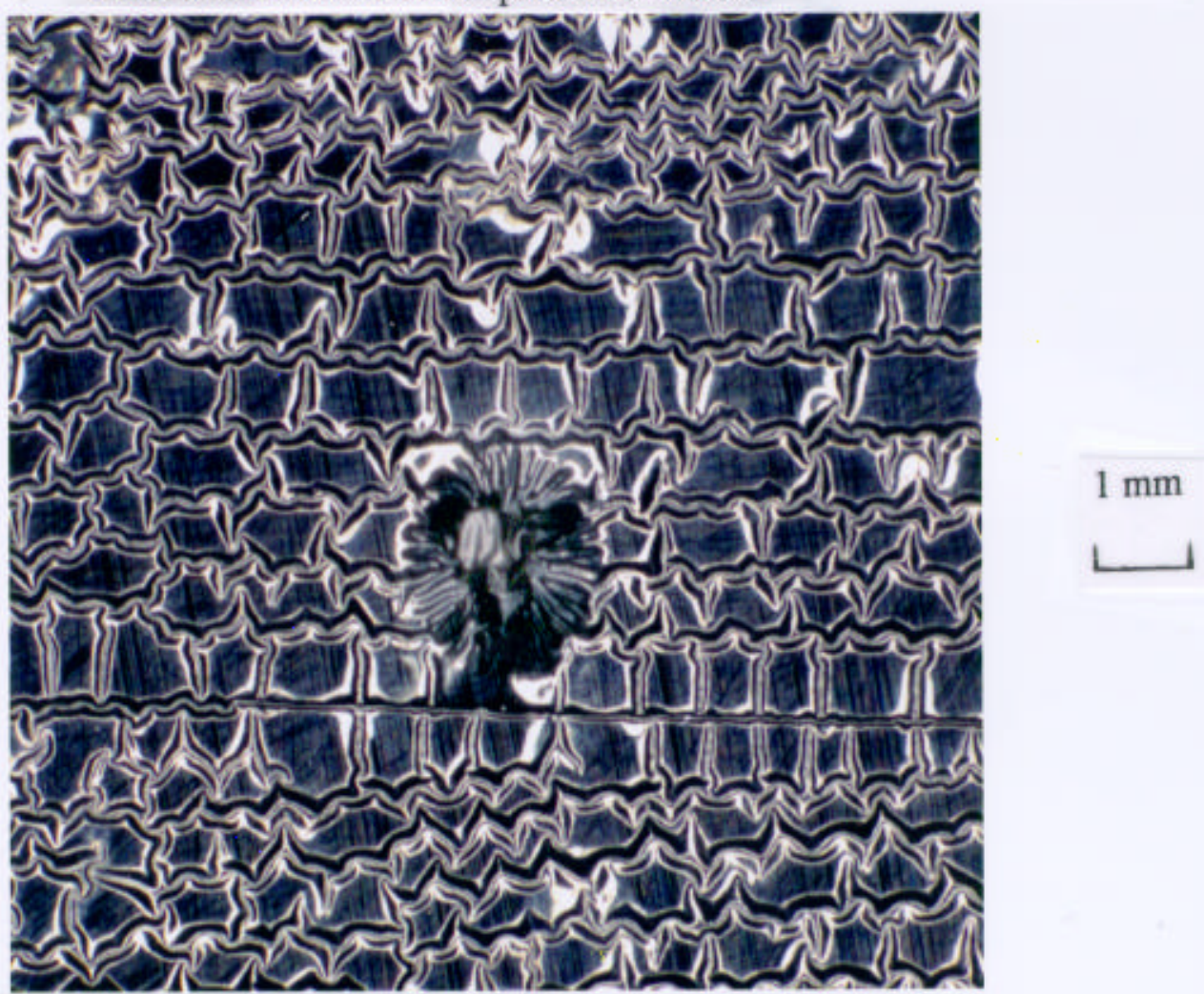

Fig. 8: Two typical undamaged targets on the carbon foil after the beam test 
Predicated maximum temperature: $>5000 \mathrm{~K}$

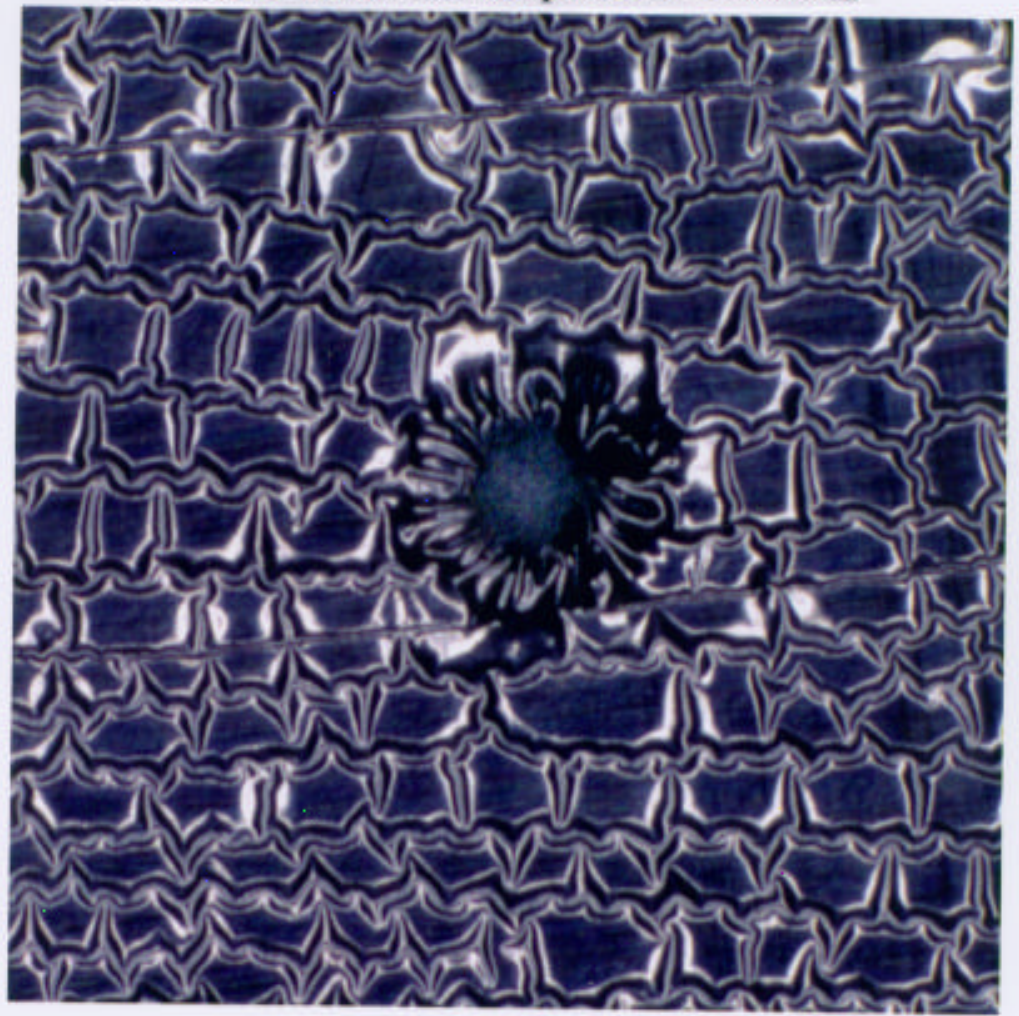

Fig. 9: A damaged target on the carbon foil after the beam test 


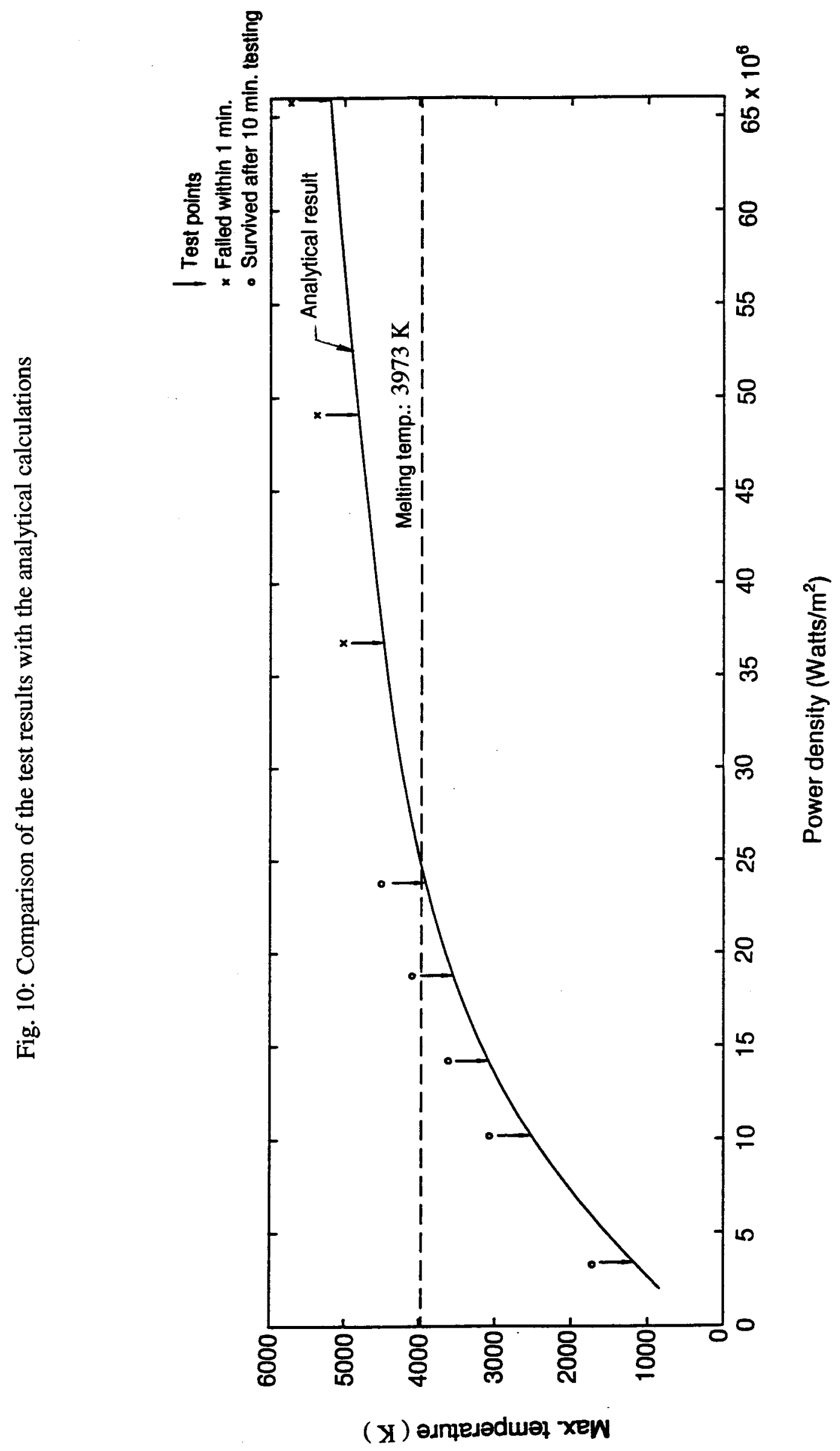

